\title{
Perspectivas e limitações do trabalho com práticas corporais de aventura na escola: um relato de experiência
}

Ivan Livindo de Senna Corrêa*

\begin{abstract}
Resumo:
Este relato objetiva refletir sobre a trajetória pedagógica do autor, suas perspectivas e obstáculos vividos no trabalho com práticas corporais de aventura na escola. Para realizar o trabalho, utilizaram-se os pressupostos metodológicos autobiográficos, em que o sujeito é ator e autor das experiências vividas. Como resultado, destaca-se o interesse do autor pelas práticas corporais de aventura, as possibilidades, os obstáculos e, como perspectivas finais, o trabalho aponta para publicações anteriores que apresentam metodologias para o ensino de arvorismo, tirolesa, rapel, parkour e slackline em todos os níveis de ensino da educação básica.
\end{abstract}

\section{Palavras-chave:}

Aventura. Escola. Educação Física.

\begin{abstract}
:
This report aims to reflect about the pedagogical trajectory of the author, his perspectives and obstacles lived in the work with corporal practices of adventure at school. For this study it was utilized autobiographical pedagogical assumptions in which the author is the subject of his lived experiences. As result, it is highlighted the interest of the author for corporal practices of adventure, the perspectives, obstacles, and ultimately, this experience points to previous publications that present methodologies to teach tree climbing, ziplining, rappelling, parkour and slacklining in all levels of teaching of basic education.
\end{abstract}

\section{Keywords:}

Adventure. School. Physical Education.

\footnotetext{
"Doutor em Educação pela UFRGS, mestre em Ciência do Movimento Humano pela UFSM, professor de Educação Física do Colégio de Aplicação da UFRGS. E-mail: ivan.livindo@ufrgs.br. ORCID iD: http://orcid.org/0000-0003-0186-6511.
} 


\section{Introdução}

Com a Base Nacional Comum Curricular (BRASIL, 2017), as práticas corporais de aventura tornam-se oficialmente um conteúdo da Educação Física escolar, porém muitos educadores já pautavam, em suas práticas, essa temática. Por exemplo, as experiências de Matiello Junior (2002) que ao tematizar a educação ambiental nas aulas de Educação Física proporcionava vivências de aventura aos seus estudantes. Diante desse contexto, este trabalho objetiva refletir sobre a trajetória pedagógica do autor, suas perspectivas e obstáculos vividos no trabalho com práticas corporais de aventura na escola.

Para realizar o relato de experiência utilizaram-se os pressupostos metodológicos autobiográficos, nos quais, segundo Medeiros e Aguiar (2018, p. 155), "o sujeito movimenta-se em uma análise entre o papel vivido de ator e autor de suas próprias experiências, sem que haja uma mediação externa de outros sujeitos”.

Assim, no decorrer deste relato, encontra-se: a trajetória vivida do autor, que o levou interessar-se pelas práticas corporais de aventura; as perspectivas para o trabalho com as práticas corporais de aventuras na Educação Física escolar; as limitações encontradas durante a trajetória com o ensino das práticas corporais de aventura; e, como perspectivas finais, aponta para estudos anteriores que apresentam metodologias para o ensino de arvorismo, tirolesa, rapel, parkour e slackline ${ }^{1}$ em todos os níveis de ensino da educação básica.

\section{A trajetória vivida com as práticas corporais de aventura}

Apresento $^{2}$ a minha trajetória com as práticas corporais de aventura, pautado na Pedagogia da Libertação de Paulo Freire, a qual procura valorizar os conhecimentos dos educandos e os saberes das experiências vividas dos sujeitos nas ações educativas. Para Freire (1993, p. 59), "se não é possível defender uma prática educativa que se contente em girar em torno do 'senso comum', também não é possível aceitar a prática educativa que, zerando o 'saber da experiência feito', parta do conhecimento sistemático do(a) educador(a)”. Essa práxis dialética de respeito ao conhecimento dos educandos, de problematização e de construção do novo, perpassa toda a prática pedagógica libertadora. Por isso, meu relato parte da minha experiência vivida, que está imbricada nas relações educador-educando, educador-educador e gestor-educador-educando.

Ao iniciar a reflexão sobre as práticas corporais de aventura surgiu a seguinte questão: o que me levou a desenvolver essas experiências pedagógicas? Ao fazer essa autoanálise, percebi que as minhas experiências corporais na infância foram baseadas em atividades corporais de aventuras. Como nasci e vivi a infância nas várzeas do rio Santa Maria, na divisa dos municípios de Dom Pedrito (RS) e São Gabriel (RS), as atividades corporais ali experienciadas foram: caminhadas nas coxilhas e várzeas; caçadas com bodoques na mata ciliar de riachos e capão de mato; pescarias no rio e açudes; escaladas (subidas) em árvores; jogo de "bolita", entre outras atividades.

As minhas experiências corporais enquanto estudante da Educação Física escolar foram limitadas à brincadeira de roda, pegador, esconde-esconde, futebol, voleibol, ginástica e atletismo. Além das aulas de Educação Física, foram significantes às brincadeiras no recreio, das quais a preferida era escalar as árvores no pátio da escola.

\footnotetext{
1. Arvorismo, tirolesa, rapel, parkour e slackline são técnicas de transpor obstáculos naturais ou urbanos. Arvorismo envolvem um conjunto de técnicas de ascensão (escalada) e de deslocamento (falsa baiana, tirolesa, ponte construída com cordas e madeiras etc.) no topo das árvores com o objetivo de observar o bioma ou como lazer. A tirolesa é o deslocamento por um cabo (corda ou aço) aéreo de um ponto a outro fazendo uso de polia. O rapel é uma técnica de descensão por corda. O parkour é um percurso com obstáculos urbanos em que o participante realiza sem auxílio de equipamentos e para completar o percurso o participante corre, salta, rola e escala. O slackline é uma técnica de deslocamento caminhando ou fazendo acrobacias de um ponto a outro sobre uma fita aérea (FRANCO, 2017; CORRÊA, 2019).

2. Embora o texto tenha sido escrito na forma impessoal, há passagens que uso a primeira pessoa do singular porque se trata de um relato pessoal de experiência.
} 
Outras experiências corporais que contribuíram com minha formação foram as realizadas no Exército Brasileiro. Essa instituição oportunizou práticas de aventuras significativas junto à natureza como: grandes caminhadas, corrida de orientação, pistas de obstáculos, rapel, comando crawl e falsa baiana ${ }^{3}$.

No curso de Educação Física na UFSM realizado no período de 1987 a 1990 na UFSM, as experiências corporais foram futebol, handebol, basquetebol, ginásticas, voleibol, atletismo, natação e recreação. As duas últimas marcaram-me muito, principalmente pelos "riscos" que elas possibilitavam, em particular na recreação comunitária, através da extensão universitária, que me estimulou a criação de brinquedos e brincadeiras de aventura.

Em 1990, no estágio docente (Santa Maria, RS), foi possível trabalhar com construção de jogos, brinquedos, brincadeiras e caminhada junto à natureza. Foi durante o estágio que se iniciou, sistematicamente, a experiência com as práticas corporais de aventura. Durante o estágio, houve a possibilidade de realizar subidas, com os estudantes da $6^{a}$ série de uma escola da rede municipal de ensino, no Morro do Elefante (Camobi, Santa Maria, RS).

Além da experiência do estágio, outra vivência significativa foi a realização das trilhas nos morros de Torres (RS), em 1989, realizadas com crianças de uma Colônia de Férias, da qual era um dos recreacionistas. Porém, foi no meu primeiro trabalho, como professor de Educação Física, numa escola rural do município de Restinga Sêca (RS), em 1993, que adotei, como um dos conteúdos da Educação Física escolar, as práticas corporais junto a natureza. Iniciei com caminhadas na mata próxima à escola, escalada em árvores e realização de tirolesa.

Pode-se dizer que as práticas corporais de aventura que venho trabalhando na escola partem das experiências vividas pelos educandos e educadores e das concepções de educação, de Educação Física escolar, de natureza e de aventura. Isso faz parte das concepções pedagógicas docentes e que, segundo Sacristán (1998), são fatores que moldam as práticas curriculares. Assim compreendido, o currículo escolar é moldado pela cultura e concepções dos professores.

A concepção de educação, como já referida, é freiriana e parte do princípio de que "ninguém educa ninguém, como também ninguém educa a si mesmo: os homens se educam em comunhão mediatizados pelo mundo" (FREIRE, 1987, p. 69). Assim, num espaço de aprendizagem, encontram-se seres humanos que possuem histórias e tornam-se sujeitos históricos que analisam e refletem sobre uma temática comum. Como resultado da reflexão educador/edudando, tem-se a síntese das percepções desses sujeitos e que, depois, de sistematizadas constituem-se em conhecimento. Na particularidade desse relato, a temática comum é as práticas corporais de aventuras, nas quais educador e educando dedicam seu tempo escolar ao estudo e à experiência corporal de aventura.

A concepção de Educação Física Escolar aproxima-se da visão crítica-superadora, a qual compreende a Educação Física como uma área de conhecimento que, em sua "prática pedagógica [...] no âmbito escolar, tematiza formas de atividades expressivas corporais como: jogo, esporte, dança, ginástica" (SOARES et al., 1992, p. 50) e capoeira que se ampliou para lutas. Essa concepção constitui-se num consenso na Educação Física escolar e está presente nos Parâmetros Curriculares Nacionais (PCNs) (BRASIL, 1998) e também na Base Nacional Comum Currícular (BNCC) (BRASIL, 2017). Sendo que, nesse último documento, introduzem-se as práticas corporais de aventura como conteúdo da Educação Física escolar.

Segundo a BNCC (BRASIL, 2017, p. 218), as práticas corpoais de aventura "exploram-se expressões e formas de experimentação corporal centradas nas perícias e proezas provocadas pelas situações de imprevisibilidade que se apresentam quando o praticante interage com um ambiente desafiador". Essas práticas podem ocorrer tanto junto à natureza como em ambientes urbanos. As práticas de aventura na natureza "se caracterizam por explorar as incertezas que o ambiente físico cria para o praticante, na geração da

3. Comando crawl e falsa baiana são técnicas de deslocamento de um ponto a outro sobre cordas, muito usadas em treinamento militar. No comando crawl, o praticante deita de decúbito ventral sobre a corda e tracionando com os braços desliza sobre a corda. Na falsa baiana, o participante desloca-se com o uso de duas cordas, uma apoiando os pés e outra apoiando as mãos acima da cabeça. 
vertigem e do risco controlado" (BRASIL, 2017, p. 218-219) e as práticas nos espaços urbanos oportunizam explorar as incertezas das edificações e espaços construidos pelo homem.

Além de ser um espaço físico, a natureza é um conceito polissêmico, só para esse relato, concebemos natureza com um princípio educativo. A concepção de natureza aqui adotada é dialética, em que o ser humano pertence a natureza. Assim, as relações humanas com a natureza são relações: homem-meio natural, homem-homem e homem-demais seres vivos. Essas relações podem contruir-se conflitivamente, em que um visa destruir o outro ou, de forma dialétia, em que um complementa-se no outro. Para Kosik (2011, p. 77), “o homem é ativamente inserido nas relações sociais, mas ao mesmo tempo tem uma determinada relação com a natureza e cria para si uma determinada representação da natureza”. Por isso, penso que, no contexto contemporâneo, o contato do homem com ambientes naturais, que ainda não foram transformados conforme a objetivação humana, constituem-se no reencontro do homem com ele mesmo.

Esse reencontro consigo mesmo pode ocorrer em outros ambientes, por exemplo: fui professor de natação por vários anos e sempre quando atendia estudantes que tinham pouco contato com o meio líquido, percebia a fragilidade, os medos e a necessidade do auxílio do outro. Essas sensações observadas desvelavam a pessoa e mostravam o ser humano que todos nós somos: frágeis, inseguros e incompletos. Para Freire (1986), os seres humanos em muitas circunstâncias são frágeis e inseguros, porém são sempre inacabados ou inconclusos e por isso necessitam do contato com outros seres, também inacabados, para se educarem mutuamente. Nesse sentido, a aventura possiblita aos seus participantes momentos de superação das suas fragilidades e inseguranças e da ampliação da compreensão de si e do mundo.

A concepção de aventura está pautada na relação homem-mundo. Relação em que, segundo Costa (2000, p. 80-81), ocorre o

[...] reencontro do homem com o imprevisto [que] o arranca à quietude que confronta as dimensões não atendidas de si e do mundo. [...] A aventura explora as possibilidades da condição humana, recusa uma indentidade limitada, é a aspiração secreta, nossa nostalgia sempre renovada.

Assim, as práticas corporais de aventura na escola possibilitam aos educandos o reencontro consigo mesmo, com o mundo e permitem a reflexão sobre as questões ambientais atuais.

Essa prática tenho desenvolvido desde 2007 no Colégio de Aplicação da UFRGS, desde o primeiro ano do Ensino Fundamental até terceiro ano do Ensino Médio, conforme já relatado em estududos anteriores (CORRÊA; GONÇALVES, 2016; CORRÊA, 2019; CORRÊA; WITTIZORECKI, [2021])

Para além das experiências vividas, a inclusão das práticas corporais de aventura como conteúdo da Educação Física escolar apresenta-se como um desafio aos professores de Educação Física. No entanto, essa inclusão leva-me a refletir sobre as perspectivas e limitações para o trabalho dessas práticas na escola.

\section{Perspectivas para o trabalho com atividades corporais de aventuras na escola}

Há perspectivas que são amplas na atualidade, principalmente porque as práticas corporais de aventura estão na moda, presentes nos meios de comunicação de massa e de interesse econômico, sobretudo, pela indústria do turismo e instituições esportivas (AURICCHIO, 2013; MARCELLINO, 2000; CORRÊA, 2019.)

Conforme Corrêa (2019, p. 150), “a demanda crescente por PCAs [práticas corporais de aventura] é fruto da relação dialética do mercado, onde a construção de necessidades coincide com a oferta do produto". Com isso, indústrias de equipamentos esportivos e empresas especializadas se aliam aos meios de comunicação de massa e oferecem práticas corporais de aventura e tudo que as envolvem como mercadorias.

Numa sociedade capitalista, onde tudo é transformado em mercadoria, as práticas corporais de aventuras são mercadorias lucrativas. Sendo uma mercadoria produzida em larga escala pela indústria do turismo, cresce a oferta dessas atividades e a busca pela ampliação de consumidores. 
Já as instituições esportivas têm transformado as práticas corporais de aventura em esportes competitivos e, com isso, cria-se um espaço de inserção dos profissionais de Educação Física que vislumbram as atividades corporais de aventuras como um campo de atuação profissional e de reserva de mercado.

Aliadas à indústria do turismo e às instituições esportivas estão as indústrias de equipamentos para a prática dessas atividades (como as indústrias de máquinas e equipamentos esportivos, equipamentos de segurança, de vestuários, de calçados, entre outras). Para conquistar o consumidor e ampliar o consumo, investe-se em marketing nos meios de comunicação de massa. Assim, as indústrias patrocinam programas específicos de atividades de aventuras e de transmissões de competições de esportes de aventuras.

Tudo isso acaba auxiliando a construção do imaginário das crianças e dos jovens e despertando o interesse pelas práticas corporais de aventuras. O interesse do mercado, por um lado, contribui para a inserção das atividades corporais de aventuras na escola e pela Educação Física. Por outro lado, o interesse de mercado impede o acesso do público aos espaços naturais, que deveriam ter acesso gratuito a qualquer cidadão. A apropriação privada dos acessos aos espaços naturais que possibilitam as práticas corporais acaba limitando essas práticas a um público restrito e economicamente favorecido.

Por isso, a inclusão das práticas corporais de aventuras na escola propicia o acesso das crianças e dos jovens às experiências que outrora eram de domínio público e hoje um privilégio de minorias. Contudo, ainda encontram-se práticas corporais junto à natureza como parte da cultura de comunidades indígenas, ribeirinhas e rurais. Por exemplo, a prática de canoagem é comum em comunidades de pescadores e ribeirinhas. Essas práticas são realizadas tanto para a subsistência, o transporte e o lazer.

Com base na concepção crítica-superadora (SOARES et al., 1992), penso que ao inserir as práticas corporais de aventuras - as quais fazem parte da cultura corporal de movimento humano, construída histórica e culturalmente - na escola, elas adquirem outros significados pedagógicos. Assim, a inserção dessas práticas no currículo escolar está além do que propõe a BNCC , porque pode:

a) ampliar o acesso às manifestações da cultura corporal de movimento humano; b) oportunizar a autorrealização dos estudantes, através da superação dos seus medos e limitações; c) possibilitar a reflexão referente ao processo de desportivização das PCAs [práticas corporais de aventura] e das privatizações dos espaços naturais favoráveis a vivências de aventura; d) envolver os estudantes no debate de questões ambientais presentes no contexto contemporâneo; e) propiciar a percepção crítica da necessidade da preservação de espaços naturais que garanta a diversidade da vida e do convívio harmonioso do homem com os demais seres vivos. (CORRÊA, 2019, p. 150).

\section{Limitações para o trabalho com atividades corporais de aventuras na escola}

As limitações para o trabalho com atividades corporais de aventura na escola pautam-se pelos seguintes aspectos: infraestrutura e espaços naturais da escola; conhecimento dos professores e relações interpessoais e de poder ${ }^{4}$.

As limitações de infraestrutura e espaços naturais fazem parte da forma que as escolas foram construídas e das comunidades onde estão inseridas. As escolas foram construídas, com a intenção de formar um contingente de trabalhadores disciplinados e com conhecimentos científicos básicos para o ingresso e permanência no mercado de trabalho. Para isso, bastam salas de aulas e um espaço para banhos de sol. São raras as escolas que dispõem de amplo espaço para as práticas da cultura corporal de movimento humano. Como afirmava Moro 5 : “[...] aqui no Rio Grande do Sul, para criar um boi é necessário um ou dois hectares e para criar um ser humano destina-se dois ou três metros quadrados", referindo-se ao inciso IV do art. $5^{\circ}$ do

4. Para Freire (1992, p. 37) o poder é uma "trama de relações, de decisões [e] de força" que, como se fosse uma teia que enlaça ou envolve sujeitos em diversas instâncias, como o fio que é tramado envolve outros fios, amarrando-os, exercendo e sofrendo pressões. 5. Fala proferida nos encontros de orientação do estágio docente, no curso de Educação Física da UFSM, 1990. 
Decreto n 69.450 (BRASIL, 1971), onde consta: "Quanto ao espaço útil, dois metros quadrados de área por aluno, no ensino primário, e três metros quadrados por aluno, no ensino médio e no superior”. É por isso que boa parte das escolas públicas disponibiliza apenas uma quadra esportiva para a prática de Educação Física.

Outra limitação material é a dificuldade para adquirir equipamentos para a prática de atividades corporais de aventuras, como: skates, bicicletas, patins, cordas, fitas, entre outros.

Quanto às limitações dos espaços naturais: são poucas as escolas que possuem árvores isoladas e bosques. Porém, as escolas rurais possuem espaços privilegiados, que favorecem as práticas corporais de aventuras.

O conhecimento do professor é outro limitante e talvez o maior, porque, em trabalhos de pesquisa (CORRÊA; MORO, 2004) que realizei na Educação Física escolar, percebi que é muito comum as aulas limitarem-se ao conhecimento do professor (ex.: quem gosta ou foi atleta de um determinado esporte acaba limitando os estudantes a prática desse esporte). Assim, as práticas corporais dos estudantes na escola ficam reféns dos conhecimentos e gostos dos professores. Por isso, a importância da formação docente, que não se resume à formação acadêmica e deve perpassar toda a vida profissional. Não basta possuir o título de graduação, o docente deve perceber que a sua formação deva ser permanente e que o estudo, a ação e a reflexão devem fazer parte do cotidiano pedagógico.

Por fim, outro limitante é as relações interpessoais e de poder. Por exemplo, quando um professor inicia a trabalhar numa escola, ele vai sentir resistências, tanto dos estudantes como dos colegas. Se esse professor propuser algo que não faça parte do senso comum daquela escola, encontrará resistências, principalmente dos colegas professores de Educação Física. Já ouvi muitos colegas aconselharem-me a não trabalhar com práticas corporais de aventura e escutei os seguintes questionamentos: "essas atividades são muito perigosas"; "se uma criança se machucar, tu serás responsabilizado"; "tu não tens formação para isso, porque não se ensinava essa atividade na tua graduação"; "a escola não possui espaços e equipamentos apropriados"; "os locais que tu estás realizando as atividades de aventuras não são apropriados".

No que se refere às relações de poder, existe resistência, tanto por parte de das direções como pelas secretarias de educação. Em minha experiência, já foi proibido oficialmente em 1993, pela Secretaria Municipal de Educação de Restinga Sêca (RS), realizar atividades em árvores, caminhadas no mato e ginástica acrobática.

Nos últimos 20 anos, encontrei algumas restrições por parte de direções escolares, como um comunicado oficial, proibindo as práticas de rapel na passarela de um dos prédios da instituição e a descida de rapel do prédio, por motivos de segurança. Assim, a direção solicitou: “[...] que as referidas atividades sejam canceladas, até que tenhamos a liberação técnica”. A aceitação das práticas corporais de aventura na escola por parte do corpo docente e das gestões tem crescido muito com a inclusão dessas práticas na BNCC, mesmo que ela possa ser motivo de crítica por diversas razões e, no que se refere às práticas corporais de aventura, tem servido como um referencial e reconhecimento do trabalho na escola.

\section{Perspectivas finais}

Este relato pautou-se em apontar perspectivas e limitações, porém não houve espaço para apresentar experiências vividas com o ensino das práticas corporais de aventuras. Neste sentido, traz-se, como conclusão, as perspectivas finais, que apontam para um trabalho sistematizado das práticas corporais de aventura em todos os níveis de ensino de educação básica. As experiências de ensino no Ensino Fundamental e Médio já relatado em trabalhos anteriores (CORRÊA; GONÇALVES, 2016; CORRÊA, 2019; CORRÊA; WITTIZORECKI, [2021]) demonstram que, apesar das dificuldades de trabalho, os educadores fazendo uso dos espaços disponíveis e de equipamentos adequados podem possibilitar aos educandos experiências de arvorismo, tirolesa, rapel, parkour, slackline, entre outros. Como estratégias metodológicas aponta-se a configuração dos espaços que permitem as experiências de aventura e, como instrumentos de avaliação, a elaboração de vídeos que possibilitem aos educandos autoavaliarem-se quanto a sua participação e aproveitamento 
das atividades. Por fim, entende-se que o relato autobiográfico exposto possa servir como referência e estímulo para a efetivação do ensino das práticas corporais de aventura na escola.

\section{Referências}

AURICCHIO, José Ricardo. Formação e atuação profissional em atividades de aventura no âmbito do lazer. 2013. Dissertação (Mestrado em Educação Física) - Faculdade de Ciências da Saúde, Universidade Metodista de Piracicaba, Piracicaba, 2013.

BRASIL. Secretaria de Educação Fundamental. Parâmetros curriculares nacionais: educação física. Brasília: MEC/ SEF, 1998.

BRASIL. Decreto $n^{\circ} 69.450$, de 1 de novembro de 1971. Regulamenta o artigo 22 da Lei número 4.024, de dezembro de 1961, e alínea c do artigo 40 da Lei 5.540, de 28 de novembro de 1968 e dá outras providências. Diário Oficial da União: seção 1, Brasília, DF, p. 8826, 3 nov. 1971. Disponível em: http://www.planalto.gov.br/ccivil_03/decreto/ D69450.htm\#textoimpressao. Acesso em: 14 maio 2017.

BRASIL. Ministério da Educação. Base Nacional Comum Curricular. Brasília, DF: MEC, 2017. Disponível em: http://basenacionalcomum.mec.gov.br/images/BNCC_EI_EF_110518_versaofinal_site.pdf. Acesso em: 24 maio 2020.

CORREAA, Ivan Livindo de Senna; MORO, Roque Luiz. Educação física escolar: reflexão e ação curricular. Ijuí: Editora Unijuí, 2004.

CORRÊA, Ivan Livindo de Senna; GONÇALVES, Mariana Barbosa Gonçalves. Práticas corporais de aventura na escola: uma experiência com o ensino médio. In: CONGRESSO SULBRASILEIRO DE CIÊNCIAS DO ESPORTE, 8., 2016, Criciúma. Anais [...]. Criciúma: UNESC, 2016. Disponível em: http://congressos.cbce.org.br/index.php/8csbce/ 2016sul/paper/viewFile/8193/4488. Acesso em: 24 maio 2020.

CORRÊA, Ivan Livindo de Senna. Práticas corporais de aventura. In: FONSECA, Denise Grosso; MACHDO, Roseli Velmonte (org.). Educação física nos anos iniciais. Porto Alegre: Sulina, 2019. p. 147-157.

CORRÊA, Ivan Livindo de Senna; WITTIZORECKI, Elisandro Schultz. Práticas corporais de aventura: experiência e sistematização do conhecimento. In: FONSECA, Denise Grosso; MACHADO, Roseli Velmonte (org.). Educação física nos anos finais. Porto Alegre: Sulina, [2021]. No prelo.

COSTA, Vera Lucia de Menezes. Esporte de aventura e risco na montanha: um mergulho no imaginário. Barueri: Manole, 2000.

FRANCO, Laércio Claro Pereira. Práticas corporais de aventura. In: DARIDO, Suraya Cristina (org.). Educação Física no ensino médio: diagnóstico, princípios e práticas. Ijuí: Editora Unijuí, 2017. p. 295-321.

FREIRE, Paulo. Pedagogia do oprimido. 17. ed. Rio e Janeiro: Paz e Terra, 1987.

FREIRE, Paulo. Pedagogia da autonomia. 6. ed. Rio de Janeiro: Paz e Terra, 1986.

FREIRE, Paulo. Pedagogia da esperança: um reencontro com a pedagogia do oprimido. 2. ed. Rio e Janeiro: Paz e Terra, 1992.

FREIRE, Paulo. Pedagogia da esperança. 2. ed. Rio de Janeiro: Paz e Terra, 1993.

KOSIK, Karel. Dialética do concreto. Rio de Janeiro: Paz e Terra, 2011.

MARCELLINO, Nelson Carvalho. Estudos do Lazer: uma introdução. Campinas: Autores Associados, 2000.

MATIELLO JUNIOR, Edgard. Exercitando conhecimentos e práticas sobre meio ambiente a partir da pedagogia crítico-emancipatória. In: KUNZ, Elenor (org.). Didática de educação física 2. Ijuí: Editora Unijuí, 2002. p. 99-131.

MEDEIROS, Emerson Augusto de; AGUIAR, Ana Lúcia Oliveira. O método (auto) biográfico e de histórias de vida: reflexões teórico-metodológicas a partir da pesquisa em educação. Revista Tempo e Espaço em Educação, Sergipe, v. 11, n. 27, p. 149-166, out./dez. 2018. Disponível em: https://seer.ufs.br/index.php/revtee/article/view/7884/pdf. Acesso em: 5 jul. 2019.

SACRISTÁN, José Gimeno. O currículo: uma reflexão sobre a prática. Porto Alegre: Artmed, 1998.

SOARES, Carmen Lúcia et al. Metodologia do ensino de educação física. São Paulo: Cortez, 1992.

Data de submissão: 12/06/2020

Data de aceite: 17/07/2020 